\title{
Corrigendum
}

\section{Corrigendum to "Sample Rocks Tests and Slope Stability Analysis of a Mine Waste Dump"}

\author{
Ping Zou $\left(\mathbb{D},{ }^{1,2}\right.$ Ximo Zhao, ${ }^{2}$ Zhonghua Meng, ${ }^{2}$ Aibing $\mathrm{Li}^{2}{ }^{2}$ Zhengyu Liu, ${ }^{2}$ and Wanjie $\mathrm{Hu}^{2}$ \\ ${ }^{1}$ School of Resource and Safety Engineering, Central South University, Changsha 410083, Hunan, China \\ ${ }^{2}$ Changsha Institute of Mining Research Co., Ltd., Changsha 410012, Hunan, China \\ Correspondence should be addressed to Ping Zou; 55709673@qq.com
}

Received 15 April 2019; Accepted 6 May 2019; Published 28 May 2019

Copyright (c) 2019 Ping Zou et al. This is an open access article distributed under the Creative Commons Attribution License, which permits unrestricted use, distribution, and reproduction in any medium, provided the original work is properly cited.

In the article titled "Sample Rocks Tests and Slope Stability Analysis of a Mine Waste Dump" [1], the article in reference [19] was cited incorrectly as "Y. Wang, P. Guo, and Y. Zhao, "Behaviour and modelling of fiber reinforced clay under triaxial compression by using the combining superposition method with the energy based homogenization technique," International Journal of Geomechanics, vol. 18, no. 1, Article ID 04017129, 2018."

The article's correct citation is "Y. X. Wang, P. P. Guo, F. Dai, X. Li, Y. L. Zhao, and Y. Liu, "Behavior and modeling of fiber-reinforced clay under triaxial compression by combining the superposition method with the energy-based homogenization technique," International Journal of Geomechanics, vol. 18, no. 12, Article ID 04018172, 2018” [2].

\section{References}

[1] P. Zou, X. Zhao, Z. Meng, A. Li, Z. Liu, and W. Hu, "Sample rocks tests and slope stability analysis of a mine waste dump," Advances in Civil Engineering, vol. 2018, Article ID 6835709, 17 pages, 2018.

[2] Y. X. Wang, P. P. Guo, F. Dai, X. Li, Y. L. Zhao, and Y. Liu, "Behavior and modeling of fiber-reinforced clay under triaxial compression by combining the superposition method with the energy-based homogenization technique," International Journal of Geomechanics, vol. 18, no. 12, article 04018172, 2018. 


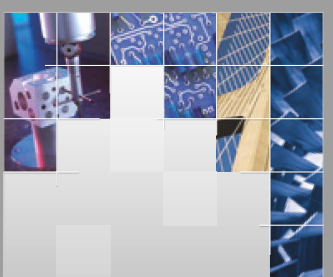

\section{Enfincering}
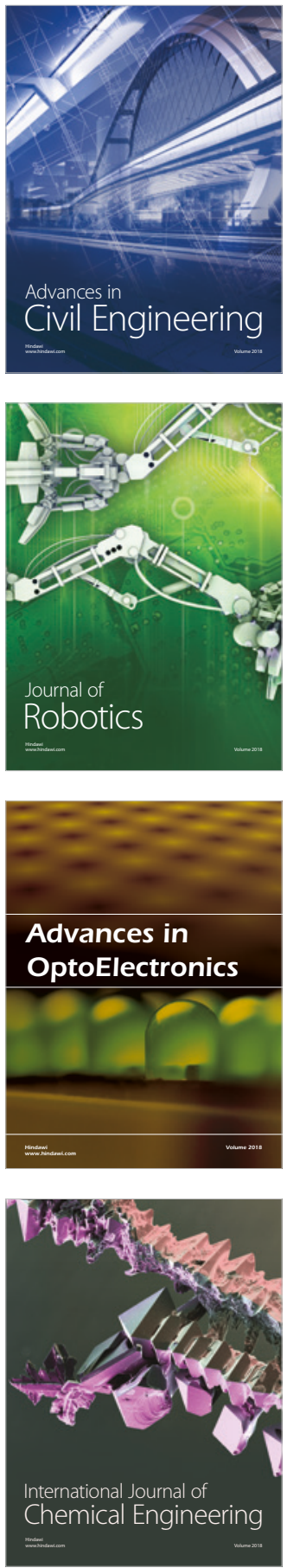

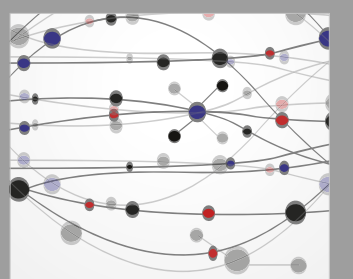

\section{Rotating \\ Machinery}

The Scientific World Journal

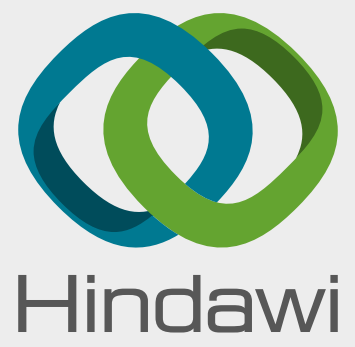

Submit your manuscripts at

www.hindawi.com
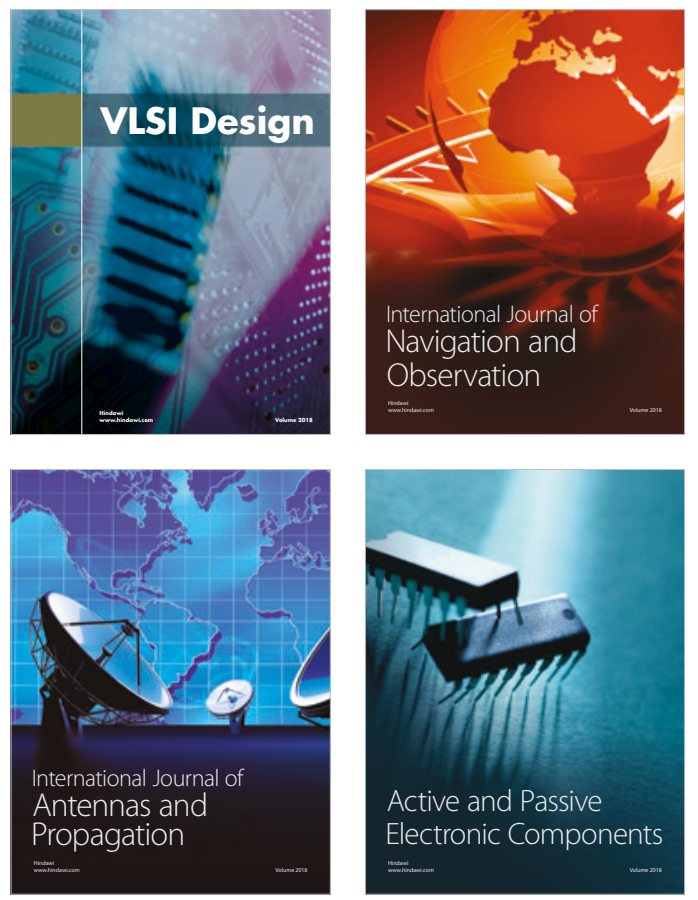
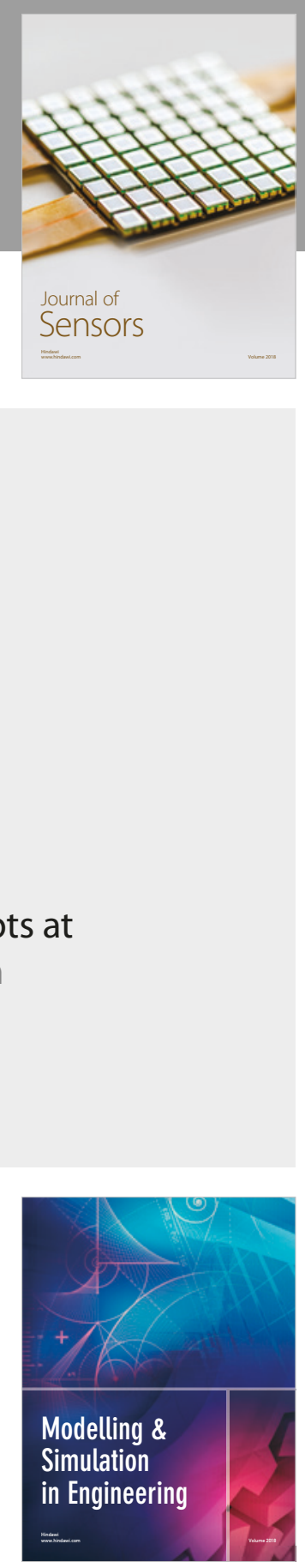

\section{Advances \\ Multimedia}
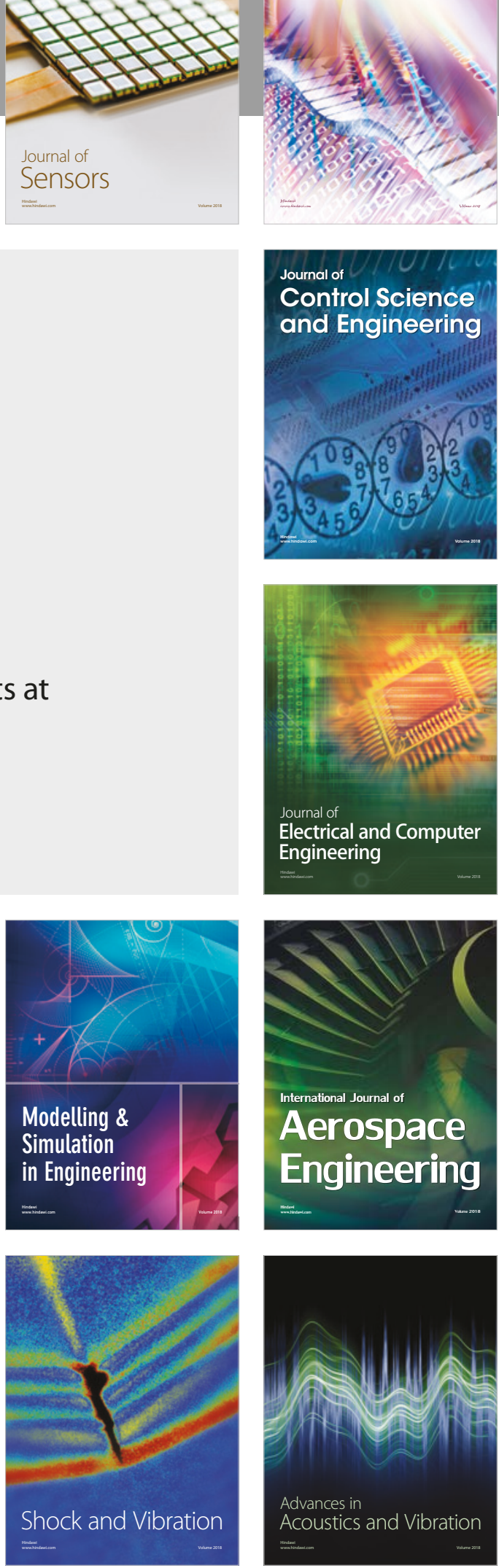